\title{
A STUDY OF PYRUVIC ACID IN THE BLOOD AND SPINAL FLUID OF PATIENTS WITH LIVER DISEASE WITH AND WITHOUT HEPATIC COMA ${ }^{1}$
}

\author{
By DONALD S. AMATUZIO ${ }^{2}$ AND SAMUEL NESBITT 2 \\ (From the Department of Medicine, University of Minnesota, and the Veterans Administration \\ Hospital, Minneapolis, Minn.)
}

(Submitted for publication June 23, 1950; accepted, August 7, 1950)

Acute failure of the liver as evidenced by hepatic coma may be ushered in by any combination of central nervous system manifestations. There is associated an oliguria or even complete anuria. Jaundice may appear or if already present may become more intense. There frequently is slight fever, leukocytosis, abdominal distention and pain.

Although the picture of hepatic coma is well recognized and, in fact, was described by ancient writers, little or nothing is known of the actual mechanism which produces it. Thus far no constant chemical or anatomic aberration has been described which may be accepted as the basic defect. The importance of the liver in the intermediary metabolism of protein, fat and carbohydrate is well known. It is quite possible that impaired intermediary metabolism may be of fundamental significance in the appearance of acute hepatic failure. To investigate this we decided to study pyruvic acid which is a focal point in intermediary carbohydrate metabolism.

1 Published with approval of the Chief Medical Director. The statements and conclusions published by the authors are the result of their own study and do not necessarily reflect the opinion or policy of the Veterans Administration.

2 Present address: Veterans Administration Center, Minneapolis, Minn.

\section{MATERIAL}

Determinations of pyruvic acid in the blood, spinal fluid, and urine were made by means of the $\mathrm{Lu}$ method (1) as modified by Friedemann and Haugen (2).

A control group of 16 surgical and orthopedic patients suffering only from mechanical disabilities was employed. A series of 31 patients without liver disease was also studied; the diagnoses in this group included renal, neurological, and gastrointestinal diseases and infections of various kinds. For reasons which will be discussed, a group of 13 patients with pulmonary emphysema was included. Thirty-five patients with liver disease, including 12 with viral hepatitis and 23 with decompensated portal cirrhosis, were studied. These patients were placed on a diet of 3,000 calories per day (C-350, P-150, F-100) with daily parenterally administered vitamins which included $110 \mathrm{mgm}$ of thiamine, $100 \mathrm{mgm}$ of ascorbic acid, $10 \mathrm{mgm}$ of menadione, $5 \mathrm{mgm}$ of pyridoxine, $50 \mathrm{mgm}$ of pantothenic acid, and $250 \mathrm{mgm}$ of niacin. All patients were on 24 hours of bed rest so as to avoid the effect of exercise which in itself will cause a slight increase in the blood pyruvic acid. Twelve of these were observed during acute hepatic failure as manifested by hepatic coma (seven with portal cirrhosis and five with homologous serum jaundice). The patients in coma received a minimal daily caloric intake of 3,000 calories by gastric intubation.

\section{RESULTS}

In the control group the mean values of pyruvic acid were $1.04 \pm 0.088 \mathrm{mgm} \%$ in the fasting blood and $1.02 \pm 0.003 \mathrm{mgm} \%$ in the fasting

TABLE I

Mean values of blood, spinal fluid and urine in various states

\begin{tabular}{|c|c|c|c|c|c|c|c|}
\hline & \multicolumn{2}{|c|}{ Blood } & \multicolumn{2}{|c|}{ Spinal Fluid } & \multicolumn{3}{|c|}{ Urine } \\
\hline $\begin{array}{l}\text { 1. Normal } \\
\text { 2. No liver disease } \\
\text { 3. Emphysema } \\
\text { 4. Hepatitis } \\
\text { 5. Severe cirrhosis } \\
\text { 6. Hepatic coma }\end{array}$ & $\begin{array}{r}n o . \\
16 \\
31 \\
12 \\
7 \\
15 \\
12\end{array}$ & $\begin{array}{c}m g m \% \\
1.04 \pm 0.09 \\
1.06 \pm 0.13 \\
0.96 \pm 0.22 \\
1.01 \pm 0.14 \\
1.54 \pm 0.23 \\
2.65 \pm 0.96\end{array}$ & $\begin{array}{l}n o . \\
12 \\
26 \\
\\
12\end{array}$ & $\begin{array}{c}m g m \% \\
1.02 \pm 0.003 \\
0.98 \pm 0.03 \\
\\
1.53 \pm 0.59\end{array}$ & $\begin{array}{r}n o . \\
12 \\
29 \\
12 \\
7 \\
15 \\
10\end{array}$ & $\begin{array}{c}m g m \% \\
1.07 \pm 0.21 \\
0.93 \pm 0.29 \\
1.15 \pm 0.29 \\
1.20 \pm 0.13 \\
2.21 \pm 1.19 \\
2.71 \pm 1.60\end{array}$ & $\begin{array}{l}\text { 24-hour total } \\
17.83 \pm 2.68 \\
13.81 \pm 4.29 \\
17.14 \pm 3.82 \\
17.71 \pm 3.62 \\
28.51 \pm 16.3\end{array}$ \\
\hline
\end{tabular}


TABLE II

Pyruvic acid in hepatic coma

\begin{tabular}{|c|c|c|c|c|c|c|}
\hline & Patient & Blood & Spinal fluid & \multicolumn{3}{|c|}{ Urine } \\
\hline $\begin{array}{l}\text { H. P. } \\
\text { E. I. } \\
\text { O. S. } \\
\text { B. S. } \\
\text { C. A. } \\
\text { C. L. } \\
\text { C. H. } \\
\text { J. H. } \\
\text { H. A. } \\
\text { A. H. } \\
\text { F. T. } \\
\text { H. K. }\end{array}$ & \multirow[t]{2}{*}{$\begin{array}{l}\text { Cirrhosis, alcoholic } \\
\text { Cirrhosis, alcoholic } \\
\text { Cirrhosis, alcoholic } \\
\text { Homologous serum jaundice } \\
\text { Homologous serum jaundice } \\
\text { Homologous serum jaundice } \\
\text { Cirrhosis, alcoholic } \\
\text { Homologous serum jaundice } \\
\text { Cirrhosis } \\
\text { Cirrhosis } \\
\text { Homologous serum jaundice } \\
\text { Cirrhosis, alcoholic }\end{array}$} & \multirow[t]{2}{*}{$\begin{array}{c}m g m \% \\
3.63 \\
2.11 \\
3.40 \\
1.70 \\
4.85 \\
2.27 \\
1.76 \\
2.47 \\
2.66 \\
1.80 \\
2.52 \\
2.37 \\
\\
2.65 \pm 0.96\end{array}$} & \multirow[t]{2}{*}{$\begin{array}{c}m g m \% \\
2.24 \\
1.08 \\
1.80 \\
0.37 \\
1.15 \\
2.02 \\
1.54 \\
2.35 \\
0.98 \\
1.57 \\
1.78 \\
1.97 \\
1.53 \pm 0.59\end{array}$} & $\begin{array}{l}m g m \% \\
3.52 \\
1.75 \\
\\
3.42 \\
6.08 \\
1.88 \\
1.36 \\
1.32 \\
2.34 \\
3.91\end{array}$ & $\begin{array}{c}\text { total vol. } \\
120 \\
900 \\
\text { Anuric } \\
700 \\
225 \\
230 \\
345 \\
400 \\
\text { Anuric } \\
700 \\
\text { Anuric } \\
900\end{array}$ & $\begin{array}{c}\text { total } \mathrm{mg} \\
4.3 \\
15.8 \\
\\
24.0 \\
13.7 \\
4.3 \\
4.7 \\
5.3 \\
15.7 \\
37.1\end{array}$ \\
\hline Mean & & & & \multicolumn{3}{|c|}{$2.71 \pm 1.60$} \\
\hline
\end{tabular}

spinal fluid. In the series of patients suffering from non-hepatic disease, the pyruvic acid values were found to be similar to the control group. There was no statistically significant difference between the values of the two groups (Table I). The control values of the fasting blood and spinal fluid pyruvic acid are in agreement with the values found by Bueding, Wortis and Stern (3) and by Friedemann and Haugen (4). In patients with viral hepatitis, excluding those who were most severely ill and in hepatic coma (to be discussed separately), the pyruvic acid determinations of the blood showed no significant statistical difference when compared with the control group. However, in patients with greatly impaired hepatic function including those with portal cirrhosis and those in hepatic

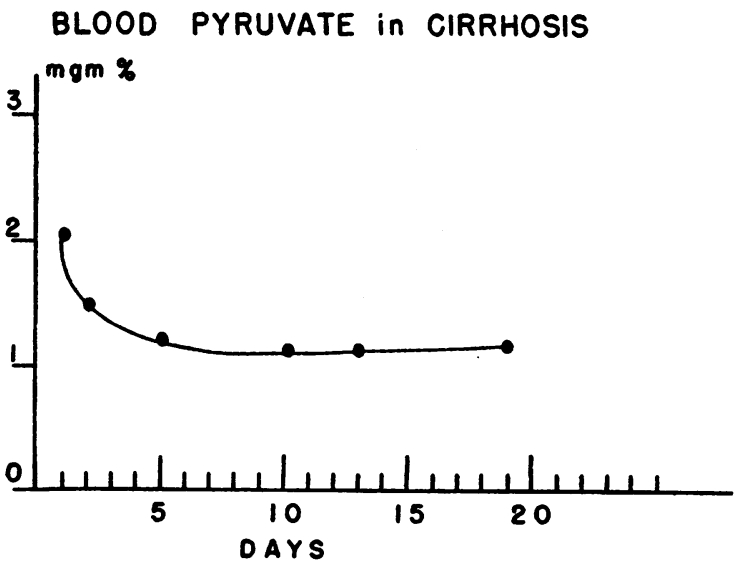

FIG. 1. coma, higher values of pyruvic acid were found in the blood and spinal fluid.

In 15 patients with decompensated portal cirrhosis the pyruvic acid values found were from 1.28 to $2.00 \mathrm{mgm} \%$ in the fasting blood. The 'mean values are tabulated in Table I. The increase in these values compared to the control group was found to be statistically significant. The blood pyruvic acid was followed over a period of time in patients with decompensated cirrhosis and a return to normal in from four to five days was noted (Figure 1).

Twelve patients were studied during periods of hepatic coma characterized by neurological manifestations including mental confusion, listlessness or agitation, disorientation, somnolence, and profound coma. Neurological findings included hyporeflexia, absent response to painful stimuli, presence of sucking reflex, positive Babinski response, and fecal and urinary incontinence. Oliguria or anuria was a constant feature. All patients had marked alteration in all of the usual liver function tests including fractional serum bilirubin, cephalin cholesterol flocculation, thymol turbidity, zinc sulfate turbidity, alkaline phosphatase, total cholesterol with esters, plasma protein value including albumin-globulin ratio, 24-hour urine urobilinogen, and prothrombin time. The diagnosis was confirmed at necropsy in 11 of these patients.

In hepatic coma pyruvic acid determinations were made on the fasting blood and spinal fluid, and on breath samples collected in distilled water 
BLOOD PYRUVATES in COMA

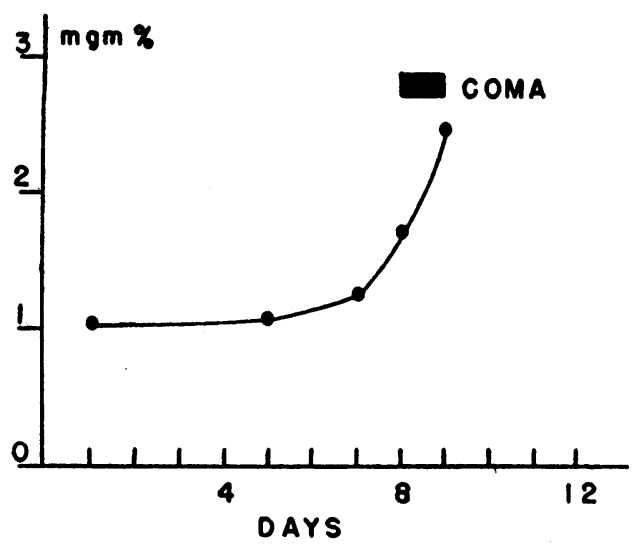

FIG. 2.

and in ethyl alcohol. No pyruvic acid was demonstrated in the breath. During coma the fasting blood pyruvic acid was found to be constantly elevated, the values in the 12 patients ranging from 1.70 to $4.85 \mathrm{mgm} \%$ (Table II). The mean value was $2.65 \pm 0.963 \mathrm{mgm} \%$. The fasting spinal fluid pyruvic acid was elevated in eight patients and the values were from 1.54 to $2.35 \mathrm{mgm} \%$; in four patients the spinal fluid values were normal, the mean being $1.53 \pm 0.597 \mathrm{mgm} \%$ (Table II). The increased values of pyruvic acid in the blood and spinal fluid in the hepatic coma group were found to be statistically significant when compared with the normal values.

Serial determinations of blood and spinal fluid pyruvic acid were made of patients in precoma and coma. Figure 2 illustrates the course of the
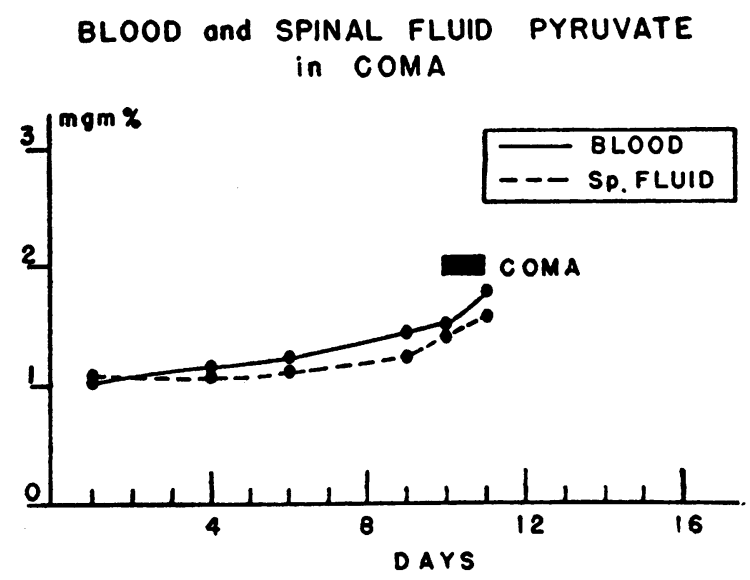

FIG. 3. blood values as the patient goes into coma. The patient J. H., age 76, had homologous serum jaundice. As the patient went into coma there was an extremely rapid rise of the pyruvic acid in the - blood during the last three days of life. The values rose from $1.25 \mathrm{mgm} \%$ on the seventh day to 2.47 $\mathrm{mgm} \%$ on the last day of life.

Figure 3 illustrates the relationship of the blood and spinal fluid pyruvic acid in patient C. G. H., age 59, with alcoholic cirrhosis. On the fifth day before death the patient became drowsy and there was noted a gradual rise in the blood and spinal fluid values. On the last day of life the pyruvic acid was $1.76 \mathrm{mgm} \%$ in the blood and $1.54 \mathrm{mgm} \%$ in the spinal fluid. The relationship of the values in blood and 24-hour urine is illustrated by patient C. L., age 56, with homologous serum jaun-

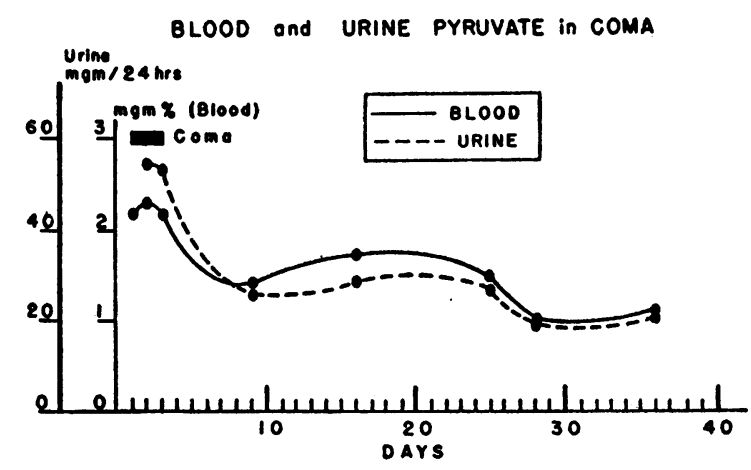

Fig. 4.

dice (Figure 4). He was first seen in hepatic coma. The initial blood pyruvic acid was 2.16 mgm\% and the patient was oliguric. He gradually improved except for a recurrence of drowsiness and disorientation on the 16th day accompanied by a rise of blood pyruvic acid.

A lowered oxygen saturation of the arterial blood has been found in patients with portal cirrhosis by Keys and Snell (5), and by Hagen and Skouge (6). Anoxia has been reported as a cause of elevated blood pyruvic acid (4). This would suggest that the elevated pyruvic acid in liver damage may be due to the associated hypoxia and not to liver failure per se. A study was undertaken to note the relationship of pyruvic acid to hypoxia in 12 patients with varying degrees of pulmonary emphysema. The arterial oxygen saturations varied from $51.1 \%$ to $93.3 \%$ with 
associated pyruvic acid values in fasting blood of from 0.72 to $1.20 \mathrm{mgm} \%$. (See Table I for mean values.) A comparison of these values with the control group revealed no statistically significant difference in the blood pyruvic acid. It is apparent that decreased arterial oxygen saturation of from $93 \%$ to $51 \%$ has no effect on the pyruvic acid of the blood. It is also apparent that if this degree of hypoxia exists in liver failure, it would have no effect on the pyruvic acid values in the blood.

Finally, the pyruvic acid values of the three groups of liver disease were compared. A definite statistically significant difference of the blood pyruvic acid values was found between the group with viral hepatitis (exclusive of coma) and that with portal cirrhosis; this was also true between the group with viral hepatitis and that with hepatic coma. A comparison of the group with portal cirrhosis and that with hepatic coma revealed a statistically significant difference of the blood pyruvic acid values (Table III). From these findings one may conclude that the degree of elevation of the blood pyruvic acid is dependent upon the degree of hepatic failure.

\section{DISCUSSION}

In the metabolism of carbohydrates, pyruvic acid occupies a central position and the reactions in this metabolic breakdown are reversible. Pyruvic acid is also a link between the metabolism of carbohydrate and protein.

Under normal conditions pyruvic acid may contribute to the formation of carbohydrate and may undergo reversible and irreversible transformation. The irreversible transformations are an oxidative decarboxylation and a complete oxidation under aerobic conditions. The reversible transformations are a reduction to lactic acid and a transamination to alanine under anaerobic conditions. Pyruvic acid incubated with liver tissue gives rise to oxalacetic, alpha ketoglutaric, succinic, fumaric, and citric acids (7). The formation of oxalacetic acid is dependent upon the $\mathrm{CO}_{2}$ fixation of pyruvic acid, and this has been shown to occur in the liver (8).

Pyruvic acid has been found to be elevated in the blood of patients with thiamine deficiency (9), alcoholic polyneuritis (3), thyrotoxicosis (10), heart failure (11), and after severe exercise. The elevation of the pyruvic acid in beri-beri, alcoholic polyneuritis, and thyrotoxicosis is due to thiamine deficiency. After severe exercise its elevation is due to a sudden release from an increased metabolic breakdown of glucose by muscle. Snell and Butt (12) have reported increased values of pyruvic acid in the blood of two patients with liver diseases who were in hepatic coma and suggested that they may result from a breakdown of certain enzyme systems (cozymase and co-carboxylase) which play a part in intermediary metabolism of glucose. In heart failure the elevation of the pyruvic acid may be related to impaired liver function due to congestion.

Factors producing the elevated pyruvic acid in liver failure are not known. It would appear that it is not due to a simple vitamin deficiency since pyruvic acid values rise steadily in progressive hepatic failure in spite of parenteral administration of large amounts of vitamins. It can only be suggested that the elevated pyruvic acid may be due to an inability of the liver to assimilate pyruvic acid to form the dicarboxylic acids necessary for the Krebs cycle. Failure of cellular aerobic metabolism may well explain the neurological manifesta-

TABLE III

Blood values in hepatitis, cirrhosis, and hepatic coma

\begin{tabular}{|c|c|c|c|c|c|}
\hline Group & No. patients & Pyruvic acid & $\begin{array}{l}\text { Diff. between } \\
\text { means }\end{array}$ & t & $\mathbf{P}$ \\
\hline $\begin{array}{l}\text { 1. Patients with hepatitis } \\
\text { Patients with severe cirrhosis }\end{array}$ & $\begin{array}{r}7 \\
15\end{array}$ & $\begin{array}{c}\text { mgm\% } \\
1.01 \pm 0.14 \\
1.54 \pm 0.23\end{array}$ & 0.53 & 5.402 & $<0.01$ \\
\hline $\begin{array}{l}\text { 2. Patients with hepatitis } \\
\text { Patients with liver coma }\end{array}$ & $\begin{array}{r}7 \\
12\end{array}$ & $\begin{array}{l}1.01 \pm 0.14 \\
2.65 \pm 0.96\end{array}$ & 1.64 & 4.459 & $<0.01$ \\
\hline $\begin{array}{l}\text { 3. Patients with severe cirrhosis } \\
\text { Patients with hepatic coma }\end{array}$ & $\begin{array}{l}15 \\
12\end{array}$ & $\begin{array}{l}1.54 \pm 0.23 \\
2.65 \pm 0.96\end{array}$ & 1.11 & 4.413 & $<0.01$ \\
\hline
\end{tabular}


tions and oliguria which are so characteristic of hepatic coma.

\section{SUMMARY}

Thirty-six patients with liver disease including 12 with viral hepatitis and 24 with portal cirrhosis were investigated. Twelve of these were observed in hepatic coma (seven with cirrhosis and five with hepatitis). Pyruvic acid levels in the hepatitis group (excluding those in coma) were normal. The group with simple decompensated cirrhosis had moderately elevated values in the blood which returned to normal in a few days. The highest values in the blood were found during hepatic coma in which group the blood pyruvic acid was constantly elevated. Serial determinations showed an abrupt rise during coma and a decline with improvement. In this group spinal fluid values were elevated in eight and normal in four. Mean blood, and spinal fluid values in the coma group were significantly higher than values in the cirrhosis group without coma and in the control group.

A series of patients with pulmonary emphysema (arterial oxygen saturation of from $51.1 \%$ to 93.3\%) gave normal blood levels. This would exclude hypoxia (reported to occur in cirrhosis) as the mechanism responsible for elevated pyruvic acid values.

The degree of elevation of blood pyruvic acid in patients with liver disease would appear to depend upon the degree of hepatic failure. The possible implications of this are discussed.

\section{BIBLIOGRAPHY}

1. Lu, G. D., Studies on the metabolism of pyruvic acid in normal and vitamin $B_{1}$-deficient states. Biochem. J., 1939, 33, 249, 774.

2. Friedemann, T. E., and Haugen, G. E., Pyruvic acid. II. The determination of keto acids in blood and urine. J. Biol. Chem., 1943, 147, 415.

3. Bueding, E., Wortis, H., and Stern, M., Pathological variations in blood and spinal fluid pyruvic acid. J. Clin. Invest., 1942, 21, 85.

4. Friedemann, T. E., Haugen, G. E., and Kmieciak, C., Pyruvic acid. III. The level of pyruvic and lactic acids, and the lactic-pyruvic ratio, in the blood of human subjects. The effect of food, light muscular activity, and anoxia at high altitude. J. Biol. Chem., 1945, 157, 673.

5. Keys, A., and Snell, A. M., Respiratory properties of the arterial blood in normal man and in patients with disease of the liver: position of the oxygen dissociation curve. J. Clin. Invest., 1938, 17, 59.

6. Hagen, P. S., and Skouge, O., Unpublished data.

7. Wood, H. G., Werkman, C. H., Hemingway, A., and Nier, A. O., Fixation of $\mathrm{CO}_{2}$ by pigeon liver in the dissimilation of pyruvic acid. J. Biol. Chem., 1942, $142,31$.

8. Evans, E. A., Jr., and Slotin, L., $\mathrm{CO}_{2}$ utilization by pigeon liver. J. Biol. Chem., 1941, 141, 439.

9. Bueding, E., Stein, M. H., and Wortis, H., Blood pyruvate curves following glucose ingestion in normal and in thiamine-deficient subjects. J. Biol. Chem., 1941, 140, 697.

10. Williams, R. H., Egana, E., Robinson, P., Asper, S. P., and Dutoit, C. H., Alterations in biological oxidations in thyrotoxicosis. J. Clin. Invest., 1942, 21, 623.

11. Yanof, Z. A., Blood pyruvic acid in heart disease. Arch. Int. Med., 1942, 69, 1005.

12. Snell, A. M., and Butt, H. R., Hepatic coma : observations bearing on its nature and treatment. Tr. A. Am. Physicians, 1941, 56, 321. 